\title{
Effect of the Substitution of Sand by Rubber of Waste Tires on the Mechanical Properties of Hydraulic Concrete and Exposure to Gamma Radiation
}

\author{
Jesús M. Colín de la Cruz ${ }^{1}$, Carmen Gabriela Guzmán1, Fermín Castillo Mejía², \\ Benjamin Leal Acevedo3, Osvaldo Flores Cedillo², Isabel Gamboa de Buen³, \\ Arturo Molina Ocampo ${ }^{4}$, Horacio Martínez Valencia ${ }^{2}$
}

\author{
${ }^{1}$ Facultad de Ciencias Químicas e Ingeniería, Universidad Autónoma del Estado de Morelos, Cuernavaca, México \\ ${ }^{2}$ Laboratorio de Espectroscopia, Instituto de Ciencias Físicas, Universidad Nacional Autónoma de México, Cuernavaca, México \\ ${ }^{3}$ Instituto de Ciencias Nucleares, Universidad Nacional Autónoma de México, México City, México \\ ${ }^{4}$ Centro de Investigación en Ingeniería y Ciencias Aplicadas, UAEM, Cuernavaca, México \\ Email: *jcolin@uaem.mx
}

How to cite this paper: de la Cruz, J.M.C., Guzmán, C.G., Mejía, F.C., Acevedo, B.L., Cedillo, O.F., de Buen, I.G., Ocampo, A.M. and Valencia, H.M. (2021) Effect of the Substitution of Sand by Rubber of Waste Tires on the Mechanical Properties of Hydraulic Concrete and Exposure to Gamma Radiation. Journal of Minerals and Materials Characterization and Engineering, 9, 245-256.

https://doi.org/10.4236/jmmce.2021.93017

Received: April 12, 2021

Accepted: May 9, 2021

Published: May 12, 2021

Copyright $\odot 2021$ by author(s) and Scientific Research Publishing Inc. This work is licensed under the Creative Commons Attribution International License (CC BY 4.0).

http://creativecommons.org/licenses/by/4.0/

\section{(c) (i) Open Access}

\begin{abstract}
For a long time and until now, rubber is the most used material for the manufacture of tires for motor vehicles. Unfortunately, once the tire meets its life cycle, the remaining rubber cannot be recycled, so the tires are discarded in collection centers and often in clandestine dumps. This represents a serious environmental problem because, in one case, these waste tires become breeding grounds for insects and wildlife that is harmful to humans. In the second case, the tires are burned, releasing highly damaging gases into the atmosphere. On the other hand, concrete is worldwide the construction material par excellence. It is basically composed of cement, gravel and sand. Mixing these three components in different proportions, their mechanical strength in compression can be increased. However, due to its fragile nature, concrete, once a crack is formed, it rapidly advances by fragmenting the material and producing its rapid collapse. In the present work, in order contribute to the care of the environment as well as to modify the fracture mode of the concrete, rubber particles obtained from waste tires were used as sand substitute in hydraulic concrete. In addition, rubber modified samples concrete were lately exposed to $70 \mathrm{kGy}$ of gamma radiation in order to study the effects of this radiation on the mechanical deformation of concrete. The results showed a decrease in the mechanical properties of the concrete with rubber particles with respect to the traditional concrete itself. However, such decreases were
\end{abstract}


offset by the fact that samples with rubber addition do not collapses as fast as the free rubber samples. The acquired data pave the way for research with great benefits, such as the use of recycled tires in concrete for its fracture mode modification in a beneficial way, as well as a possible decrease in the cost of concrete.

\section{Keywords}

Hydraulic Concrete, Scrap Tire Rubber, Strength, Gamma Radiation, Mechanical Properties

\section{Introduction}

For many years, while a large percentage of vehicle tires have been reprocessed and used, a bigger lot of them have been accumulated in special places or simply thrown in public areas, posing serious threats to the environment and public health. A large quantity of worn tires are deposited in untreated controlled landfills, whereas some other amount is deposited after being crushed, and the rest is not controlled. In order to eliminate these residues, direct burning is frequently performed, which causes serious environmental problems since it releases gases that contain particles harmful to the environment [1].

Nowadays, various methods can be used for the recovery of tires and the destruction of their dangerous components. Furthermore, the operations of reuse, retreading, and recycling of used tires represent an important opportunity for the industry and technology [2]. The worn tires have three main components [3], which provide the tire with a vibration absorption capacity, reduced weight, high cut resistance, high resistance to weather conditions, and flexibility.

1) Rubber. Excellent mechanical properties, including elasticity in traction, bending, and in compression.

2) Metal. Steel of very good quality and performance, recyclable in iron and steel companies.

3) Fiber. Material of a great calorific value and with good acoustic and thermal insulation properties.

For the present work, the first component is that of a major interest.

On the other hand, concrete made with Portland cement has a wide range of applications that allow multiple possibilities of use. All types of concretes have been proven over time to have excellent properties and a high degree of durability and resistance, which can be seen in large buildings, public works, or artistic groups located in harsh conditions (near the sea). The excessive consumption of construction materials such as concrete, leads to excessive consumption of raw materials, which are usually found in nature. Since the extraction of natural resources has the most significant impact on the environment generating environmental and landscape effects, in order to reduce the ecological impact that this entails, efforts have been made to reduce the consumption of nonrenewable 
natural resources during the manufacture of concrete. In addition, entities responsible for the protection of the environment have limited the access to these resources [1] [4], however, these environmental problems lie not only in mining, but also in the issue of waste generation, such as tires, which increase proportionally with the number of vehicles. The environmental problem of tire waste is generated by the limited knowledge of waste management plans, owing to both cultural issues and the lack of policies and research on the reuse and final disposal of this type of waste. Considering the previous scenarios, such as the excessive generation of tires and insufficient final disposal sites and the shortage of stone resources, in an attempt to make adequate use of excess rubber from scrap tires, several research works have been carried out [4] [5] [6] [7], so, it can be considered that the reuse of tires as recycled material within building construction materials presents a means to contribute to the environmental, technical, and economic benefit for the society [4] [5]. In this way, several years ago, Toutanji [4] proposed the utilization of rubber tires in concrete for several specific applications, such as noise barriers, electricity posts, and plants of asphalt [4]. A viable solution to the problem caused by scrap tires is to use tire elastomers in concrete as a substitute for the fine or coarse aggregates, ensuring the quality of the product and, if possible, increasing desirable properties such as strength, Young's modulus, and durability. In spite of that it is well known that mechanical properties of the concrete are not enhanced by rubber additions, in the present work, the authors propose its use as a modifier of fracture mode as well as crack fast breakthrough inhibitor. In this research work, the rubber particles obtained from car waste tires were used as a sand substitute for reinforcement in hydraulic concrete. In addition, the effect of aging on physical properties of concrete with rubber additions will be also considered since it has been reported that the performance of rubber materials, gradually downturn when during a long period of service they are exposed to oxygen, ozone, sun light, heat, and so on [8]-[14] which suggest they are vulnerable to the aging process.

\section{Experimental Setup}

Four different mixtures of cement, gravel, sand, and rubber were prepared according to the compositions shown in Table 1 , substituting the sand by waste tire rubber scratches of about $1.0-1.5 \mathrm{~mm}$ diameter and $5-15 \mathrm{~mm}$ long, at 5 and 10 and $20 \mathrm{wt} \%$.

Each mixture was poured into a mold to obtain a continuous bar of $5 \mathrm{~cm}$ (height) $\times 5 \mathrm{~cm}$ (width) $\times 30 \mathrm{~cm}$ (length). At the end of the pouring process, four square section bars of $5 \mathrm{~cm}$ (side) $\times 30 \mathrm{~cm}$ (length) were obtained. Figure 1 shows two representative bars.

Afterwards, each bar of specific composition was sectioned to obtain six cubes of $75 \mathrm{~cm}^{3}$. From each bar, three cubes were separated to be aged by its exposition to gamma radiation, keeping the remaining three as the control patterns. The cubes to be irradiated were subjected to gamma radiation (70 kGy doses) with cobalt-60 using a Gamma beam 651-PT irradiator at variable dose rates with $90 \mathrm{kCi}$. 


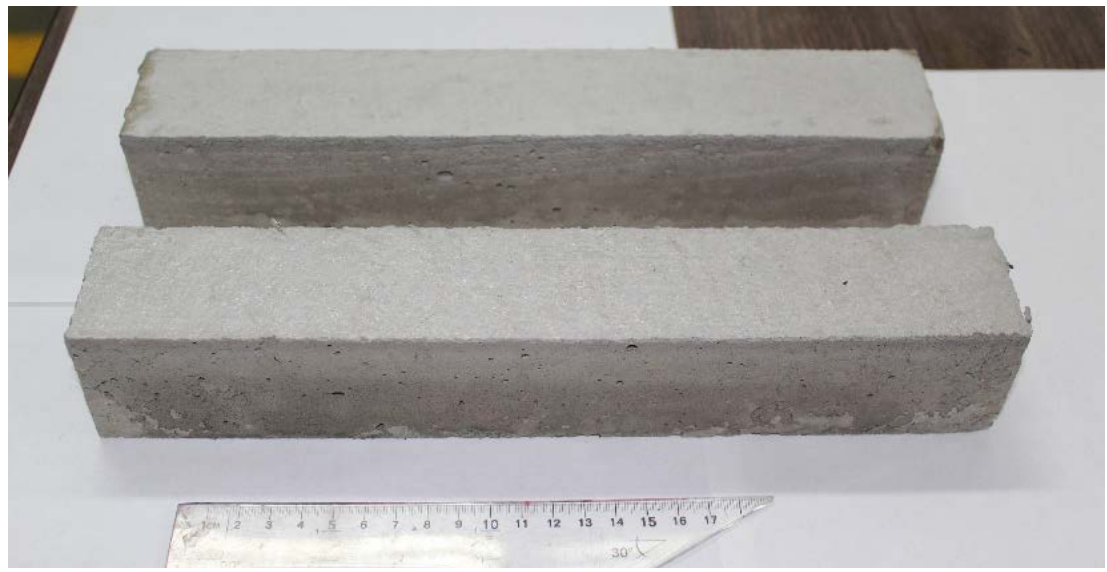

Figure 1. Continuous concrete bars of $5 \mathrm{~cm}$ (height) $\times 5 \mathrm{~cm}$ (width) $\times 30 \mathrm{~cm}$ (length) obtained after $24 \mathrm{~h}$ from casting.

Table 1. Amounts $(\mathrm{kg})$ of cement, gravel, sand and rubber used in the study. The cement used was Portland CPC type 30. a/c $=0.58$.

\begin{tabular}{cccccc}
\hline Sample & Sand & Rubber & Cement & Gravel & Water (mL) \\
\hline M (0) & 0.51460 & 0 & 0.282 & 0.7998 & 200 \\
M (5) & 0.48887 & 0.02573 & 0.282 & 0.7998 & 200 \\
M (10) & 0.46314 & 0.05146 & 0.282 & 0.7998 & 200 \\
M (20) & 0.41168 & 0.10292 & 0.282 & 0.7998 & 200 \\
\hline
\end{tabular}

Then, the irradiated (R) and the no-irradiated (SR) cube samples were mechanically characterized by performing compression tests in an Instron universal machine for mechanical tests, Model 4206 , with a capacity of $150 \mathrm{kN}$, at a crosshead rate of $0.5 \mathrm{~mm} / \mathrm{min}$.

Stress-strain curves were obtained, in which fracture stress was determined using a strain criterion of $0.01 \%$. Likewise, the modulus of elasticity was calculated using Equation (1) according to the criterion established by the American Concrete Institute [15].

$$
E_{0}=4700 \sqrt{f_{c}^{\prime}},
$$

where $E_{0}$ is the modulus of elasticity $(\mathrm{MPa})$ and $f_{c}^{\prime}$ is the fracture stress of concrete (MPa).

\section{Results}

\subsection{Mechanical Properties}

The results of the mechanical tests are shown in Table 2 as well as in Figure 2 as fracture stress versus strain and Figure 3 as fracture stress versus rubber content curves of the samples at different rubber rates and states of the studied compositions. It is important to mention that in the present research work, the first change of slope observed in the stress vs strain graph was taken as the fracture stress of the sample under study, assuming that such change in the slope was 


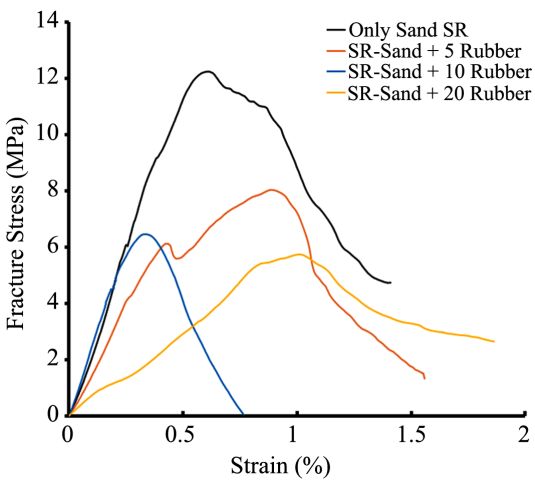

(a)

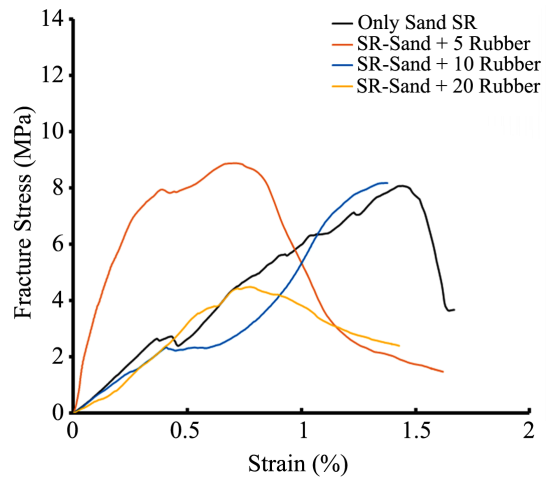

(b)

Figure 2. Fracture stress vs strain curves obtained in the samples at different compositions and states. SR: Non Irradiated; R: Irradiated.

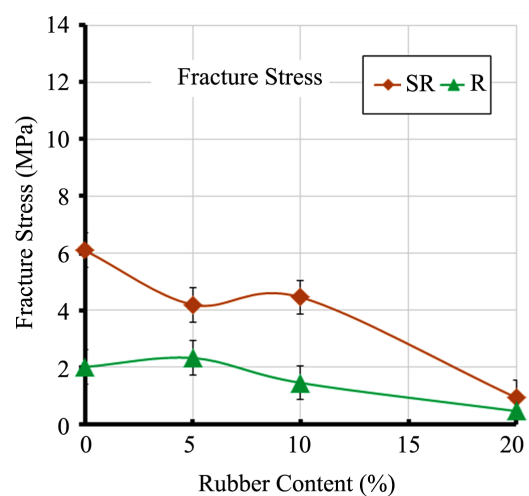

(a)

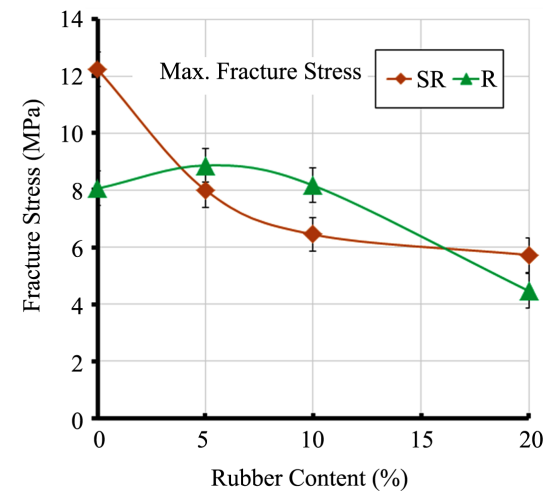

(b)

Figure 3. Mechanical behavior observed in the concrete samples as a function of the rubber content. (a) Fracture Stress; (b) Maximum Fracture Stress.

Table 2. Mechanical properties of the samples under study.

\begin{tabular}{|c|c|c|c|c|c|c|c|}
\hline \multirow{3}{*}{ Sample } & \multirow{3}{*}{$\begin{array}{c}\text { Rubber } \\
\text { content } \\
\text { (wt } \%)\end{array}$} & \multicolumn{6}{|c|}{ Sand substitution by rubber } \\
\hline & & \multicolumn{3}{|c|}{$\mathrm{SR}^{*}$} & \multicolumn{3}{|c|}{$\mathbf{R}^{*}$} \\
\hline & & $\begin{array}{c}\text { Fracture } \\
\text { stress } \\
(\mathrm{MPa})\end{array}$ & $\begin{array}{c}\text { Strain } \\
(\% *\end{array}$ & $\begin{array}{c}\text { Maximum } \\
\text { Fracture } \\
\text { Stress (MPa) }\end{array}$ & $\begin{array}{c}\text { Fracture } \\
\text { stress } \\
(\mathrm{MPa})\end{array}$ & $\begin{array}{c}\text { Strain }^{* *} \\
(\%)\end{array}$ & $\begin{array}{c}\text { Maximum } \\
\text { Fracture } \\
\text { Stress (MPa) }\end{array}$ \\
\hline$M(0)$ & 0 & 6.10 & 0.256 & 12.24 & 2.02 & 0.0473 & 8.06 \\
\hline$M(5)$ & 5 & 4.20 & 0.255 & 8.01 & 2.33 & 0.040 & 8.87 \\
\hline $\mathrm{M}(10)$ & 10 & 4.46 & 0.183 & 6.45 & 1.460 & 0.256 & 8.17 \\
\hline $\mathrm{M}(20)$ & 20 & 0.94 & 0.138 & 5.73 & 0.469 & 0.117 & 4.47 \\
\hline
\end{tabular}

${ }^{*}$ SR: not irradiated. R: irradiated. ${ }^{*}$ Strain at fracture stress.

produced by the cracking or micro cracking anywhere in the sample. Likewise, the maximum stress value observed in the stress vs strain graph was taken as the maximum stress supported by the specimen before the decrease in stress begins.

It can be observed that rubber additions produces a decrease in the mechanical property of Fracture Stress of the SR sample, see Figure 3(a), being 31.14\% 
for $M$ (5), $26.88 \%$ for (M10) and $84.59 \%$ for $M(20)$ sample. The Maximum fracture stress was also affected exhibiting $34.55 \%, 47.3 \%$ and $53.18 \%$ decreases corresponding to the M (5), M (10) and M (20) SR samples, see Figure 2(b). In both cases, the lowest stress values belong to the M (20) sample with $20 \mathrm{wt} \%$ rubber. These results are in agreement with Holmes et al. [16], who reported that significant reductions in compressive strength could be avoided if the addition of crumb rubber in concrete specimens does not exceed $20 \%$ of the total, although in the present work, it was used rubber scratches instead of crumb rubber.

Figure 3(a) shows that, regarding fracture stress, the strongest samples are those that were not irradiated (SR), starting with sample $M(0)$ which exhibit a 6.1 MPa fracture stress, followed by samples $M(5), M(10)$, and $M(20)$, which exhibited 4.2 MPa, 4.46 MPa, and 0.94 MPa fracture stress, respectively. On the other hand, the weak samples were found to be those exposed to the gamma radiation dose of $70 \mathrm{kGy}$. In this case, the highest fracture stress value was 2.33 $\mathrm{MPa}$, corresponding to the M (5) sample, followed by the sample with $0 \mathrm{wt} \%$ rubber, which shows a $2.02 \mathrm{MPa}$ fracture stress. Samples with $10 \mathrm{wt} \%$ and 20 wt\% rubber showed 1.46 and $0.469 \mathrm{MPa}$ fracture stress, respectively.

In the same way, Figure 3(b) shows the maximum fracture stress values of the samples in both states, irradiated (R) and not irradiated (SR). It can be observed that the highest values of 12.24 MPa and 8.01 MPa correspond to the $\mathrm{M}(0)$ and $M$ (5) samples respectively. On the other side, the sample $M$ (10) exhibit 6.45 $\mathrm{MPa}$ and sample M (20), 5.73 MPa. In spite of such maximum fracture stress values are small, they are about twice higher than that of the fracture stress, which means that, although the sample is "cracked", it is capable to supporting big load before it collapses completely.

When the mechanical properties of SR samples were compared with those exposed to gamma-radiation, it was clear that the radiation exposure did not have a beneficial effect on the fracture stress of all of the samples, since there was a large decrease in the mechanical resistance, being the largest that of the $M$ (10) sample followed by $\mathrm{M}(0)$ sample, in which a $67.26 \%$ reduction and $66.88 \%$ reduction in mechanical resistance respectively was observed. Conversely, the lowest decrease corresponded to the M (5) sample with $5 \mathrm{wt} \%$ rubber observing a mechanical resistance reduction of approximately $44.5 \%$. At the end, apparently, the most promissory composition was that of $5 \%$ rubber, which represents the second-best value of fracture stress. In contrast, apparently the gamma radiation has a beneficial effect on the Maximum Fracture Stress of the M (5) and M (10) samples since the values of such compositions are higher than the SR ones and even a little higher than the M (0) R as it can be seen in Figure 3(b). The results in some way support the observed by Martinez-Barrera et al. [17] [18] who reports that gamma radiation produces structural and surface modifications in the components of a polymeric concrete, improving the compatibility between the polymer components and the aggregates of the polymeric concrete. It 
has been reported that gamma radiation degrades the materials structure and can cause fracture in ceramic and polymers such as concrete and rubber [19] individually. Regarding the rubber, this may be the result of scission of the polymer chains due to high energy radiation, affecting the tensile strength, hardness, elastic modulus and elongation at break [20] [21]. In the case of concrete, the radiation dehydrates it and becomes more fragile. In the present research, it is observed that the irradiated M (5) and M (10) samples increased their maximum fracture stress which suggests that radiation effect on the mixture of concrete and rubber is lower in comparison when the materials are exposed individually.

As it can be expected, the elastic modulus was also affected by the rubber introduction to the concrete. Figure 4 shows a graph where it can be appreciated an irregular behavior of the decrease in the elastic modulus in the SR condition and a little more regular behavior in the $\mathrm{R}$ condition.

The highest values were $11,608 \mathrm{MPa}$ and $9926 \mathrm{MPa}$ showed by the $\mathrm{M}(0)$ and M (10) samples respectively, in the SR stage. Such decrease represents approximately $14.5 \%$, which is a reasonable value considering that the concrete contains rubber. On the other hand, the $\mathrm{R}$ samples showed a uniform decrease, but such values of elastic modulus were lower than the exhibited by the SR samples. In this case, the highest values were $6678 \mathrm{MPa}$ and $7174 \mathrm{MPa}$ corresponding to the $M(0)$ and $M(10)$ radiated samples respectively. In this stage, the corresponding elastic modulus increase was of $7 \%$ approximately. Ganjian et al. [22] studied non-irradiated concrete with chipped rubber as aggregated replacement and ground rubber as cement replacement and obtained $17 \%-25 \%$ reduction in modulus of elasticity when the aggregate replacement with chipped rubber was between $5 \%-10 \%$. On the other hand, $18 \%$ - 36\% reduction was obtained when powdered rubber was used. In the present research, scratched rubber was used in rates similar to that used by Ganjian, and although lower elastic modulus values were obtained, the decrease in such elastic modulus is lower than the reported by Ganjian. However, a remarkable result in this research is the increase in elastic modulus in the irradiated M (5) sample.

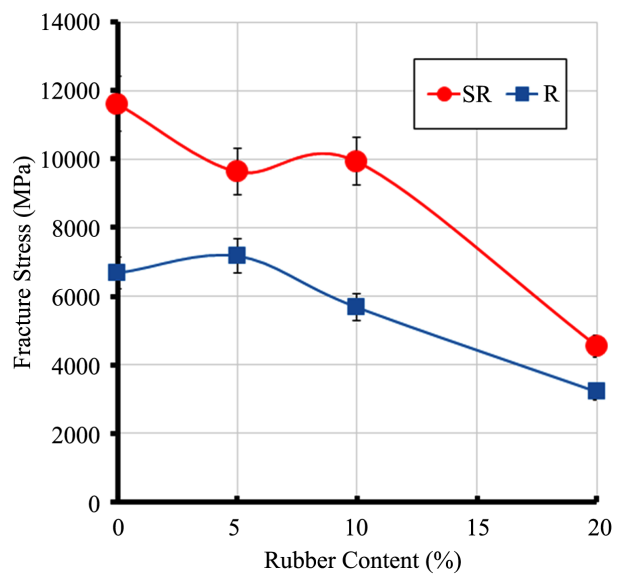

Figure 4. Elastic modulus behavior as a function of the rubber content and stage of the samples. 


\subsection{Cracking and Fracture Characterization}

Figure 5 shows the cracking observed in both SR and R samples after the compressive tests. It can be observed that the samples without rubber, see Figure 5(a) and Figure 5(b), exhibit wide cracks that produced catastrophic fractures, leading to a complete fragmentation and subsequent disintegration of the sample, as well as loss of all the mechanical strength and total collapse.

Otherwise, samples with $5 \mathrm{wt} \%$ rubber and $20 \mathrm{wt} \%$ rubber can be seen in Figure 5(c) and Figure 5(d) where it is observed that the cracks in these samples are thinner than those observed in the samples without rubber; however, despite these cracks, the samples remained complete, without disintegration, exhibiting additional resistance and deformation, see Figure 3, that allows a slow collapse instead of the sudden one observed in the samples without rubber. Such behavior suggests that this material could be potentially useful for buildings.

Fracture observations were also made on the samples under study. Figure 6 shows representative images of the fractures seen in the samples without and with rubber. It can be observed that the specimen without rubber, Figure 6(a), exhibits the presence of only a mixture of cement and sand with gravel and some small cracks indicated by the arrows. In addition, the characteristics of a brittle fracture, such as a smooth surface, which indicates a lack of cohesion between

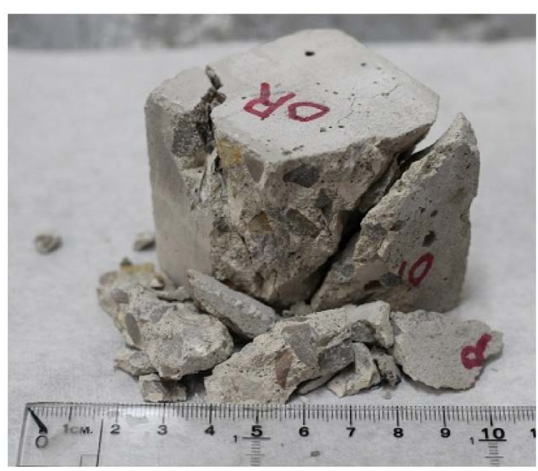

(a)

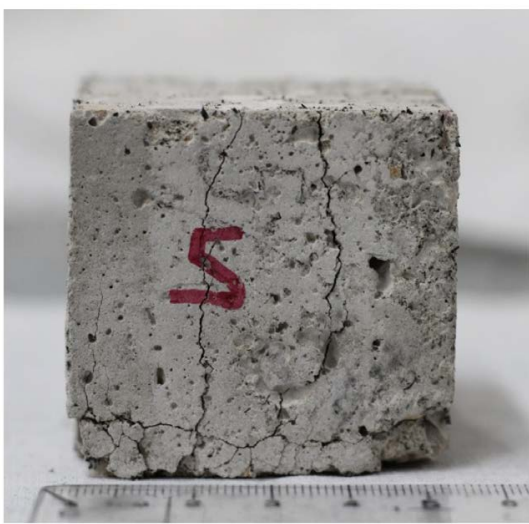

(c)

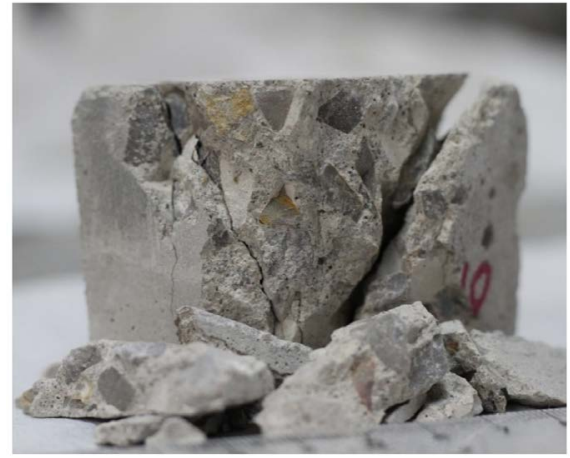

(b)

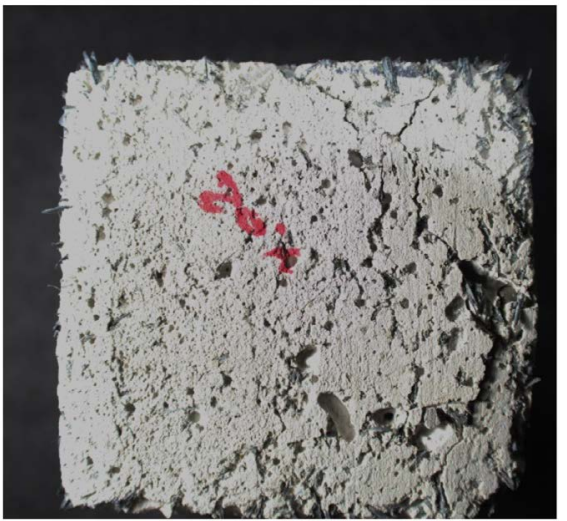

(d)

Figure 5. Concrete samples after mechanical tests in which the maximum compressive deformation was $4 \%$. ((a), (b)) $0 \mathrm{wt} \%$ rubber, (c) $5 \mathrm{wt} \%$ rubber, and (d) $20 \mathrm{wt} \%$ rubber. 


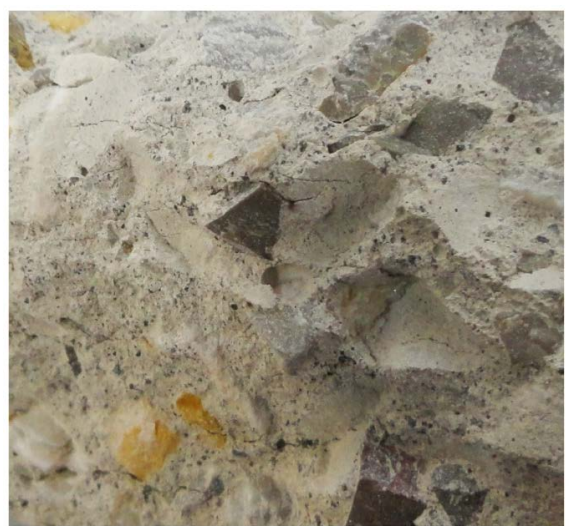

(a)

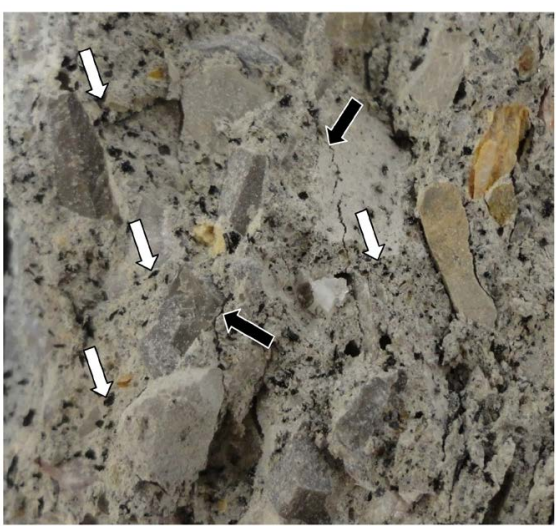

(b)

Figure 6. Top view of the fractures observed. (a) In the specimen without rubber. (b) Specimen with rubber scratches.

the fragments, promoting its easy separation, cleavage, and subsequent disintegration, were also observed. In the same way, the fracture of specimen with rubber, see Figure 6(b), also exhibits a mixture of cement and sand with gravel, but unlike the previous, the sample with rubber show characteristics of a high toughness fracture, in addition to a homogenous distribution of rubber scratches indicated by the bright arrows and the presence of some small cracks indicated by the black arrows.

Closer observations of the cracks in the samples with and without rubber were performed. Figure 7(a) is a close up of a crack in which it can be appreciated a single and growing crack that separates the sample in two pieces as a result of the lack of cohesiveness, decreasing the load resistance and leading to a subsequent collapse of the material as it can be seen macroscopically in Figure 5(a) and Figure 5(b).

On the other hand, an important finding in the fracture of the sample with rubber was the presence of some rubber scratches holding together the two pieces of material separated by a crack in several zones of the sample as it can be seen in Figure 7(b). In the specimens containing rubber scratches, the polymeric material seemed to be acting like "anchors" that keep a certain grade of union between the pieces through thin cracks, preventing the rapid growing of the crack in the material due to its intrinsic fragility, see Figure 7(b). Otherwise, in the samples that did not contain rubber scratches, internal cracks formed and propagated through the matrix of cement and sand and even through the gravel separating them completely, causing the disintegration and collapse of the material, see Figure 7(a).

It is clear that rubber scratches cannot avoid the cracking of the material, but apparently, they can decrease the fast advance of cracks and eventually stop the crack at a certain limit determined by the intensity of the load supported. Basically, striped rubber avoids the abrupt separation of the fractured parts and, therefore, the disintegration and collapse of the material. 


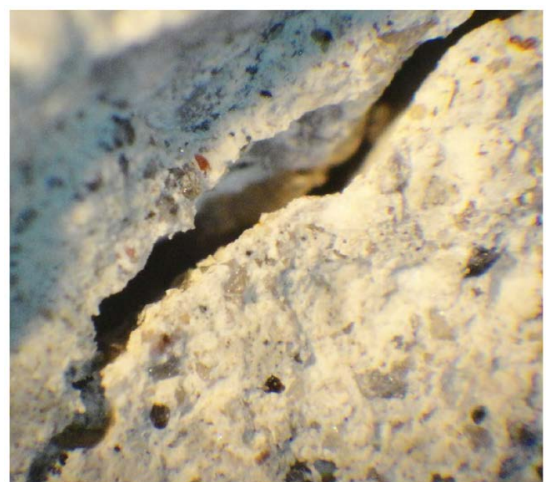

(a)

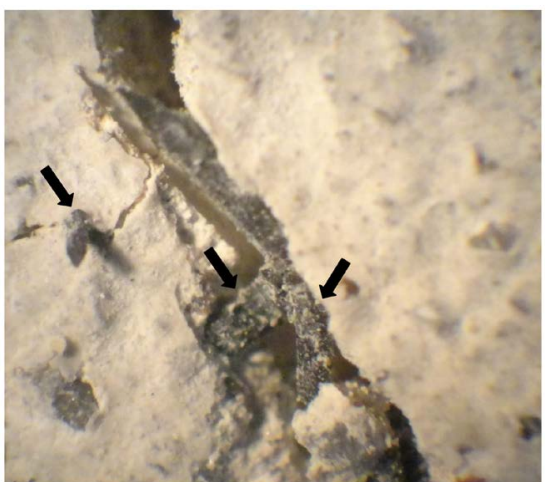

(b)

Figure 7. Photomicrographs of the fractured surfaces in the specimen; (a) without rubber; (b) with rubber.

\section{Conclusions}

The substitution of sand with rubber produces changes in the mechanical resistance of concrete as well as in its elastic modulus. A decrease in fracture stress was observed when rubber is added to the concrete. Such decrease was expected since the rubber is a soft and elastic material. Otherwise, sand is a hard and non-elastic material. However, in the present research it was observed that samples without rubber show high mechanical resistance, but a fragile behavior, rapid fragmentation, and collapse of the material once cracks appear, leading to a catastrophic fail. On the other hand, specimens including rubber exhibit relatively low mechanical resistance but also show an elastic-like behavior where slow fragmentation and slow collapse of the material are observed once the cracks appear. In addition, specimens with rubber show additional load support once their fractures stress was reached. This is apparently due to the fact that long rubber scratches act like "anchors", holding together the concrete fragmented pieces and offering additional resistance to the collapse of the sample.

Gamma radiation produces a $67 \%$ decrease in the fracture stress and $34 \%$ decrease in the maximum fracture stress of the samples without rubber. In the samples with rubber, approximately $54 \%$ average decrease in the fracture stress of the samples was registered. Opposite case was observed in the Maximum Fracture Stress registered in the M (5) and M (10) samples where the gamma radiation produced an increase of approximately $19 \%$ average. Therefore, it is assumed that the applied dose of gamma radiation affects the fracture stress of the samples in a non-beneficial way, being such effect, major in samples without rubber. Otherwise, apparently gamma radiation affects in a beneficial way the maximum fracture stress of the samples with $5 \mathrm{wt} \%$ and $10 \mathrm{wt} \%$ rubber. This probably can be due to the radiation affects mainly the surface of the specimens but not the inner components such as the rubber. This prevented internal structural changes in the components of the concrete, produced by the gamma radiation.

In the present research, there were used rubber scratches as fine aggregate 
substitute and the obtained results give support to the observations made by Holmes et al, on the fact that more than $20 \%$ replacement of rubber in concrete specimens can produce significant decrease of the compressive strength.

These results pave the way for research with great benefits, including, on one hand, the use of recycled scrap tires in concrete and, on the other hand, the improvement of the samples properties manipulating the rates of the concrete components and the aging can increase the mechanical resistance instead of decreasing it.

\section{Acknowledgements}

The authors are grateful to H. H. Hinojosa for their technical assistance. DGAPA IN-102916. To A. Aguilar Negrete, J. Macedonio Andrés and L. Brito Rodriguez from TAMULBA, FCQeI-UAEM and G. Aramburo y S. García from FQ-UNAM for their technical support. To the Collaboration agreement UNAM-UAEM No. 42467-2177-8-IX-15.

\section{Conflicts of Interest}

The authors declare no conflicts of interest regarding the publication of this paper.

\section{References}

[1] Clark, C., Meardon, K. and Russell, D. (1991) Burning Tires for Fuel and Tire Pyrolysis: Air Implications. United States Environmental Protection Agency, Office of Air Quality Planning and Standards, Research Triangle Park.

[2] Turer, A. (2012) Recycling of Scrap Tires. In: Achilias, D., Material Recycling, IntechOpen, London, 195-212. https://doi.org/10.5772/32747

[3] Dhir, R.K., Limbachiya, M.C. and Paine, K.A. (2001) Recycling and Use of Tyres. Thomas Telford, London.

[4] Toutanji, H.A. (1996) The Use of Rubber Tire Particles in Concrete to Replace Mineral Aggregates. Journal of Cement and Concrete Composites, 18, 135-139. https://doi.org/10.1016/0958-9465(95)00010-0

[5] Siddique, R. and Naik, T.R. (2004) Properties of Concrete Containing Scrap-Tire Rubber-An Overview. Waste Management, 24, 563-569. https://doi.org/10.1016/j.wasman.2004.01.006

[6] Blessen Skariah, T. and Ramesh Chandra, G. (2016) A Comprehensive Review on the Applications of Waste Tire Rubber in Cement Concrete. Renewable and Sustainable Energy Reviews, 54, 1323-1333. https://doi.org/10.1016/j.rser.2015.10.092

[7] Ishtiaq, A., UmerAmmar, M. and Nouman, K. (2015) Use of Rubber as Aggregate in Concrete: A Review. International Journal of Advanced Structures and Geotechnical Engineering, 4, 92-96.

[8] Wei, H., Guo, L., Zheng, J., Huang, G. and Li, G. (2015) Effect of Nanosilica-Based Immobile Antioxidant on Thermal Oxidative Degradation of SBR. RSC Advances, 5, 62788-62796. https://doi.org/10.1039/C5RA08951D

[9] Guo, L., Lei, H., Zheng, J., Huang, G. and Li, G. (2013) Synthesis of Nanosilica-Based Immobile Antioxidant and Its Antioxidative Efficiency in SBR Compo- 
sites. Polymer Composites, 34, 1856-1862. https://doi.org/10.1002/pc.22591

[10] Yahya, Y.R., Azura, A. and Ahmad, Z. (2011) Effect of Curing Systems on Thermal Degradation Behavior of Natural Rubber 413 (SMR CV 60). Journal of Physical Science, 22, 1-14.

[11] Chou, H.W., Huang, J.S. and Lin, S.T. (2007) Effects of Thermal Aging on Fatigue of Carbon Black-Reinforced EPDM Rubber. Journal of Applied Polymer Science, 103, 1244-1251. https://doi.org/10.1002/app.24967

[12] Vinod, V.S., Varghese, S. and Kuriakose, B. (2002) Degradation Behavior of Natural Rubber-Aluminum Powder Composites: Effect of Heat, Ozone and High Energy Radiation. Polymer Degradation and Stability, 75, 405-412. https://doi.org/10.1016/S0141-3910(01)00228-2

[13] Mao, Z., Wang, W. and Mao, G. (2021) Improving the Thermal Aging Resistance of $\gamma$-Vulcanized Polybutadiene Rubber (BR)/Nature Rubber (NR) Blends with Sulfur Added. Advances in Materials Science and Engineering, 2021, Article ID: 5782539. https://doi.org/10.1155/2021/5782539

[14] Zulkafal, H.M., Asif, M., Yasin, T., Kanwal, S., Khan, M.A. and Iqbal, K. (2018) Study of Thermal Oxidative Ageing and Gamma Irradiation Effects on Styrene Butadiene Rubber/Boron Carbide Based Composites. Journal of Chemical Engineering \& Process Technology, 9, 2. https://doi.org/10.4172/2157-7048.1000379

[15] ACI CODE-318-11: Building Code Requirements for Structural Concrete and Commentary.

[16] Holmes, N., Browne, A. and Montague, C. (2014) Acoustic Properties of Concrete Panels with Crumb Rubber as a Fine Aggregate Replacement. Construction and Building Materials, 73, 195-204. https://doi.org/10.1016/j.conbuildmat.2014.09.107

[17] Martínez-Barrera, G. and Brostow, W. (2009) Fiber-Reinforced Polymer Concrete: Property Improvement by Gamma Irradiation. In: Gamma Radiation Effects on Polymeric Materials and Its Applications, Research Signpost, Kerala, 27-44.

[18] Martínez-Barrera, G., Martínez Cruz, E. and Martínez-López, M. (2012) Concreto Polímerico Reforzado con Fibras: Efecto de la Radiación Gamma. Revista Iberoamericana de Polímeros, 13, 169-178. https://doi.org/10.4067/S0718-07642013000400008

[19] Mostafa, A., Abouel, K., Bayoumi, M.R. and El Sayad, M.G. (2009) Effect of Carbon Black Loading on the Swelling and Compression Set Behavior of SBR and NBR Rubber Compounds. Materials and Design, 30, 1561-1568. https://doi.org/10.1016/j.matdes.2008.07.043

[20] Markovic, G., Marinovic-Cincovic, M., Jovanovic, V., Samarzija-Jovanovic, S. and Budinski-Simendic, J. (2009) The Effect of Gamma Radiation on the Ageing of Sulfur Cured NR/CSM and NBR/CSM Rubber Blends Reinforced by Carbon Black. Chemical Industry and Chemical Engineering Quarterly, 15, 291-298. https://doi.org/10.2298/CICEQ0904291M

[21] Scagliusi, S.R., Cardoso, E.C.L. and Lugão, A.B. (2018) Effect of Gamma-Radiation on Thermal Ageing of Butyl Rubber Compounds. 4th Brazilian Conference on Composite Materials, Rio de Janeiro, 22-25 July 2018, 1-6.

https://doi.org/10.21452/bccm4.2018.04.03

[22] Ganjian, E., Khorami, M. and Maghsoudi, A.A. (2009) Scrap-Tyre-Rubber Replacement for Aggregate and Filler in Concrete. Construction and Building Materials, 23, 1828-1836. https://doi.org/10.1016/j.conbuildmat.2008.09.020 